\title{
Legitimacy in International Law; Functions and Elements
}

\author{
Salam Abdullah Hassan ${ }^{a}$ \\ A \\ PhD Candidate \\ Graduate School of Social Sciences \\ Near East University
}

Article History: Received: 11 January 2021; Accepted: 27 February 2021; Published online: 5 April 2021

\begin{abstract}
In the context of international law and international institutions, legitimacy as a concept has received a considerable amount of attention from scholars as well as political players on a global scale. This is while the issue remains as ambiguous and un-scrutinized as legitimacy has been used/abused based on context, which has led to recent confusions and inconsistency. This article endeavors to create a better understanding upon the matter of legitimacy as a concept by providing definitions and introducing various relevant means as well as provision of insights regarding the usage of the term within the borders of international law. As the topic remains a complex matter, this paper uses most relevant and recent scholarly works of this field to shine light upon the concept of legitimacy within international law. Issues, processes, aspects, functions and elements of legitimacy have been noted throughout this paper in terms of international context to further provide a comprehensive information regarding the state of legitimacy in modern world. Uncertainty remains an issue in this context as there is no consensus in the international atmosphere of law and governing bodies. Thus, this article emphasizes on providing clear information of how various factors have led to this complex state. International lawyers have shown an interest in the recent years regarding legitimacy and this may be of aid for further clarification of effects and relevant elements. Thus, increased participation of such actors on international scale is encouraged for provision of consensus in terms of legitimacy and surrounding debates and ambiguities.
\end{abstract}

Keywords: Legitimacy, International Law, Political Science, International Relations

\section{Introduction}

Scrutiny and vigilance are addressed towards national systems of power regarding governing laws. Democratic procedures and the constitutions of human rights have a consensus and consistency regarding exercise of power and its legitimate form within the nations that have established liberalization through democracy (Western Nations). However, this subject requires further exploration and examination as well as understanding within the scope of international law as exercise of power has been a subject of justifications. To move beyond national borders and imply democracy on an international level has faced considerable challenges that majority have not been solved. Debates and discussions as well as scholarly works are constant regarding this matter as it is necessary to imply legitimacy on international scale beyond national borders. This is while the question of legitimacy have been ongoing for a considerable period of time. Philosophy, political sciences, international relations and other fields have focused on this notion. On a more recent shift, international lawyers have shown to have paid attention on a vivid degree to this matter.

\section{Legitimacy and Its Definition}

As a term, legitimacy has been referred to as a variety of meanings, which has been used by various roles in the international context such as activists, politicians, scholars and journalists. Due to this frequent usage of the term with having an array of implications in terms of meaning, the systemization of this concept has faced a challenge . Based on time, space and the field, of which legitimacy has been used, the definition has changed. However, there is a distinguished notion, which aids in this manner. It has been noted that the word can be referred to as a meta-definition to consist and involve all aspects of legitimacy to their extent of possibility. This is while majority of studies have focused on a singular implication of the word that can be relevant to justice or forms of democracy. This concept has seen a rise in terms of attention on a sustainable basis in recent years. Thus, word, concept and conceptions have been noted as previously mentioned regarding to the word used in various manners to conceptual meta-definition, which addresses an array of conceptions regarding legitimacy. This may have caused confusion as in some reviews the legitimacy has been dismissed. It is also noteworthy that such criticize is regarding the specific usage of the word "legitimacy". Similarly, it is to be noted that some works consist of legitimacy concerns and emphasis. However, they may not comprehend the full extent of legitimacy, which can then be criticized. It was suggested that the emergence of a legitimate government was first formed in France in the 16th century as a morally-related sense, which differs from lawful form of government2. Furthermore, legitimacy has reached within the context of international law from the work of Talleyrand's principle of law, which had a more political essence than law principles.

\section{Legitimacy in International Context}


Considering linkage with international law, legitimacy has been neglected for a long period, which the negligence can be derived from a number of factors that can be as a) it has been relatively new that the concept of legitimacy has been linked to forms of power (public) that are not violent vividly and can be used as a mean of justification by scholars or philosophers. The fact that on its traditional form, international law did not consist of coercion regarding sanctions, led to the point, where international law scholars did not investigate this linkage earlier ; b) delegation of power to international institutions have been unprecedented in terms of proliferation after the second world war and consequent fall of the Berlin Wall. Thus, the traditional concept of consent has been challenged regarding international level of states having a tendency towards modern settings of justification regarding power and its exercise1; c) breaching norms of international context have changed to be stricter than before towards international regimes regardless of the dampening effect of their operating functionality outside their borders. Such notions has led to the point, where international law as a concept is no longer regarded as a mere technicality or process, which 'other people' are merely affected by ; and d) international law being proven as a mean for being complied with and not a sole conception derived from positive morality of writers regarding this subject.

Participants in international governance are to be investigated in terms of their legitimacy on various levels such as, international, regional and domestic. Nexus of their powers can be a measurement regarding their legitimacy. However, it is important to note that only the origin of gained power may not represent the full extent of their legitimacy. Additionally, the method and approach of the actor regarding exercise of their power is another mean for evaluation and examining the extent of legitimacy of that party. As this subject is complex by nature, it is crucial that both sides of legitimacy regarding participants of global actors (as well as regional) be considered and taken into account. This research is looking into the concept of legitimacy and surrounding topics that are most relevant and recent in this regard. The aim of this paper is to provide a better understanding of the subject alongside contributing to the field by highlighting key points and notions. It is thus to be noted that legitimacy in terms of exercise is to be distinguished with legitimacy in terms of origin. Hence, a separation arises regarding legitimacy as in source of power as well as exercising the power. Considering the usage of terminology, which varies from debate to debate, the concepts of two aforementioned factors in terms of legitimacy has been persistent11. Throughout the literature of the topic, a number of variations have been provided to address the previously mentioned terms of legitimacy that can be namely, original legitimacy and conduct legitimacy, instant and continual legitimacy, or representative and participatory democracy .

In regard to legitimacy in the context of international law, four major school of thoughts have been noted . It is to be noted that these schools can be resembled as contradictory to one another. Accordingly, one of these schools has been emerged from the theories of Carl Schmitt, from which emphasis is given to national law, when compared to international law. Based on this thought process, adjustments to the international law are in accordance with the interests of the state hosting it. Therefore, the extent of which the international law can be executed or implied is under the control of that state. The next school of thought emphasizes on changes occurring in the global context and focuses on the entities that have international roles are to be redefined and their impact on governments requires boosting if deemed necessary. Moreover, NGOs that are not reliant on governments have been noted to be separated and disengaged from laws that are applied on the domestic/national level. Furthermore, these entities are to conduct their operations under direct surveillance of international law to be able to function on an efficient level. Hence, the contradictory notion can be seen from the two first school of thoughts that are provided in this section.

As for the other two schools of thoughts that have been stated, a contradiction cannot be seen on a vivid level. In other words, these two schools can be considered as complementary schools regarding their conceptual settings. The extent of legitimacy and fostering it as well as acceptability on an international scale and within the scope of international law is the focus of one school. Consequently, this particular view does not emphasize on the formation of new institutions (internationally) as it focuses on the means of development of traditional forms in regard to the globalization and its increased pace on a global scale. The developed contents can be determinacy, symbolic validation, coherence and adherence. Conduct of international relations and the impact of national parliaments is the concern of the next school of thought. This school embodies normative developments in terms of governing bodies on a global scale, which can be considered as governmental domains.

It is to be noted that this particular school of thought has the underlying conceptualization that within international governance as a context, international law has reached a significant level, from which it can have vivid effects. Thus, the legitimacy of a governing body is required regardless of its level15. Legitimacy and crises have been intertwined in terms of usage. The two concepts address the lines of order and its contradictory term, chaos. A number of crises within the scope of international level has been the forces that have merged and shaped international law after the fall of Berlin Wall. In some cases, a problem solving approach to a particular crisis has placed the international law in the context. This is while in some cases, the international law could have been the cause of difficulties or sufferance for a party. Hence, due to the considerable number of crises, which have occurred, the legitimacy extent of international actors have been questioned alongside the legal system in place and international norms surrounding such issues. This became more vivid in Kosovo bombings and the consequent occurrences as well as the invasion of Iraq in 20031.

After 1990 and as a follow-up to the Power of legitimacy among Nations published by Thomas Franck, there has been a rise of attention given to the context of international law and its linkage with legitimacy. This surge 
of scholar attention towards the subject of legitimacy and international law has emerged a response from experts in the field with outstanding or distinguished status such as James Crawford and Martti Koskenniemi. It is important to highlight the fact that the criticism towards the notion of legitimacy has been derived from the standpoint, which allows strategic usage of the word based on its complex nature and varying definitions with no or little concern towards consistency. In addition, the concept of legitimacy is a subjective term, which can be considered as a contradiction with law. This is due to the provision of privilege regarding institutions that is not compliance with the totality of the setting that is implied within. It has been noted that some parties may regard a subject as legitimate or illegitimate based on their personal agenda/emotions and to express it rather than the actual examination and strategized conceptualization of the issue at hand. This provides a manner of authority for that particular party. Similarly, legal discourse can be replaced by the legitimacy discourse and critiques have noted that this in fact is a path that is sought. As previously mentioned, the military involvement with the case of Kosovo and NATO was noted to be both illegal and legitimate at the same time. Furthermore, the lack of normative content regarding claims of legitimacy has been another subject that has faced criticizing and challenges. It is important to note that due to this complex nature of the subject at hand, the perception and judgement upon legitimacy requires further comprehension and more systematic approach towards the phenomenon to create a pathway for proper implications as well as flow of unity in the international law regarding legitimacy issues. Yet the question remains that whether or not a particular party is legitimate within the scope of international law and if a singular approach is adequate in addressing this subject. In addition, responsibility of the parties involved and which one can be determining the extent of legitimacy is another issue that can be considered.

\section{An Overview on Legitimacy and International Law}

Having reviewed the literature of the topic, it can be seen that the concept of legitimacy has been linked to be an element, which can enhance the path towards complying with the law. Submission to a rule that is existing can be achieved through creation of sense of obligation and commitment towards that rule if the parties involved are convinced. This can be stated as if a particular rule is not deemed as a match to a state's interests, then that state may show disobedience towards that rule. In this notion, legitimacy can be of significant influence, as if legitimacy is solid, the state is nonetheless obliged to comply with the rule regardless of it being not intact with their interests. As previously mentioned and it can be seen throughout this paper, the concept of legitimacy can be perceived differently depending on the context that it is used. It is also important to note that the issues of legitimacy and its relation to international legal discourses is considerably new . The aforementioned notion has merged from the argument presented by Thomas Franck following the Cold War in an article called "Legitimacy in the International System". He argued that at the time, the majority of scholars have paid a significant amount of attention towards the notion of legality, while legitimacy was largely neglected26. Since his argument, the notion of legitimacy and its context has been growing in the attention span of scholars as well as political players . Moreover, it is noteworthy that the concept of legitimacy has taken a shift in terms of debates and discussions from a mere international law perspective to forms of democracy and/or criteria for individual governments and their legitimacy. Another point to be considered is that primary sources of international law and their legitimacy per se is varied from the legitimacy of the governing bodies within a state. The aforementioned shift in terms of emphasis and attention towards the notion of legitimacy has led to a point, where legitimacy and its linkage with international law lacks a fundamental and general criterion23.

As it was mentioned earlier in this paper, legitimacy has been defined in various manners based on the context. Referring to Oxford dictionary, legitimacy can be described as "conformity to the law", whereas it has also been described as "justification and/or acceptance of political authority". The latter description of legitimacy has been commonly used and accepted among scholars of political sciences as well as within the body of international law as a whole. However, it can also be noted that the two mentioned descriptions are intact as the former can lead to the latter. Nevertheless, it can be deduced that a government or authority can be considered as a legitimate body as long as the compliance with positive law has been established. This is while to consider that such notion is narrow and requires further clarification to be a mere determinant of legitimacy.

The statement that legitimacy can have varying definitions regarding the context that it is implied in was also noted by Chris Thomas in Concept of Legitimacy and International Law . As previously noted, legitimacy can be regarded as three distinctive categories that are namely, legal, moral and social. Legal legitimacy is referred to as validity that resides from positive laws. It can be said that this form of legitimacy is regarded towards degree of compliance with specific rules (positive) that are relevant. Moral legitimacy can be described as the right to rule. In other words, the moral obligation towards supporting a rule, system, action or actor can be referred to as moral legitimacy, which is in turn the property of that rule or system. The moral obligation then requires a specific action by its essence. A key point is that this particular approach is different from the positive law and its perception. In the context of moral legitimacy, the legal concern of whether a rule is binding or now is not the emphasis, rather the moral values intact with that rule is the main focus. Furthermore, social legitimacy is the last category of legitimacy, which can be referred to as a form of legitimacy that is not towards objective values of the party that is addressed. It can be said that this type of legitimacy is a belief regarding a notion and whether or not it is morally or legally considered as a legitimate rule, action or system. Thus, this form does not represent the actual properties and quality of an object as it shows perceived qualities of that object through the perspective of others. Hence, it can be said that social legitimacy is a subjective form of judgement. 
In the light of what was mentioned above, it can be said that international law and legitimacy regarding it is within the scope of the three categories introduced in this article. Additionally, the framework and setting of legitimacy in its normative form can be related to legal and moral legitimacy . In this context, normative legitimacy is mainly focused on addressing reasons (objective) for a moral, political or legal concept to be in existence. This is while social form of legitimacy is regarded as a descriptive set for assessment of opinions and not the qualities that are referred to the ruler as objective measures1. As it can be seen, legitimacy cannot be predicted by one element23. Considering compliance with a specific rule, it has been noted that merely social legitimacy can be a determinant. If a rule is perceived as a legitimate one (subjectively), the behavior of the entity in this regard can be greatly influenced. In absence of legal or moral legitimacy, objective dimensions can pose as irrelevant, especially if legitimacy is still perceived. This however, does not imply that these concepts are irrelevant. It has been stated that subjective perspectives of legitimacy can be influenced by objective ones. Legal legitimacy can be a predictor of subjective perceptions regarding an action. Based on the context and/or situation, legal legitimacy may fall behind from moral legitimacy, considering that some actions that are not legal by essence are subject to being taken as a legitimate action. An example would be the case of Kosovo, which was mentioned earlier in this paper. A key note is that legitimacy in terms of its outcomes is mainly based on social form of legitimacy. The subjective perception of legitimacy leads to creation of behaviors based on that perception. Nevertheless, it is vital to consider the role of both legal and moral legitimacy as they are foundational bedrocks for emergence of social legitimacy. Henceforth, behaviors of parties involved in the international scene can be influence regarding compliance to certain rules based on the premises of social legitimacy.

\section{Function of Legitimacy - International Court of Justice (ICJ)}

Legal disputes among states is presented to UN's ICJ for advice and legality in terms of jurisdiction . It was noted by Simmons and Danner that the concept of adherence requires totality in terms of approach that takes "all or nothing". Proceedings of ICJ can be conducted by independent prosecutors and initiated by Security Council . States under ICJ have shown their engagement through commitment regarding ICJ in the context of international law and relatively international crimes . Promotion of respect for humanitarian law on international scope as well as human rights is a major aspect of ICJ and parties involved have shown confirmation as well as compliance with this notion as it can enhance the path towards establishment and increasing the extent of freedom, justice and security . International rule of law and its development was a key objective in regard to the court to be able to function. The treaty of Rome exhibits laws of domestic scale that are relatively modern and have detailed bindings and rules. Criminal procedures as well as detailed rules have been consistent with the Rome Statute as an international court. As mentioned previously, the independent prosecutor is a vital element for the court as a feature, which allows the court to induce proper and solid legal laws as a political force. It has been stated that the court "embodies idealistic, largely legalistic conceptions of international norms that were pursued doggedly by international legal experts from the end of World War II onward ."

\section{Function of Legitimacy - Performance}

Early performance of the ICJ has been reported to be of significant positivity. This is while the functionality of ICJ in terms of consisting and comprehending all aspects of international law as well as the extent of independence of judges has faced challenges in terms of criticism and questioning . Bias, especially from national and cultural scopes have been noted to be existing in the international adjudication of members as well as judges37. Similarly, the bias of judges was shown regarding the state that appoints them and the extent of similarity of that state to their homeland. In addition, the legitimacy of the court has been under question as the arbitrary seats and the distribution of them has had a negative impact. The ability of legitimate adjudicator of the court has been challenged and constrained by the lack of ability to address and sum reservation as declarations or clause. It is noteworthy that a notable number of representatives of regimes have stated their intentions regarding application of limits on the jurisdiction of the court

\section{Elements of Legitimacy}

Following the literature of the topic and the work of Thomas, three distinctive elements have been highlighted in terms of legitimacy that are as below:

\section{A. Objects}

When legitimacy is applied to norms, action or systems it can be distinguished from the previously mentioned notions as categories of legitimacy . To evaluate the legitimacy of any of these objects, the treatment and process can and is to be distinguished from others as the context differs and as extension, facts also vary from case to case and object to object. Accordingly, the invasion of Iraq by the US in 2003 can be regarded as an illegitimate action considering moral aspects regardless of the fact that whether US is supported as a major power in the international scale or not. This is while the US government has challenged the restrictions (norms) of the time regarding the legitimacy on claims of act of self-defense. Similarly, failure of the Security Council in terms of prevention of invasion was also criticized on the international scene as a legal body (system) and thus, its legitimacy was questioned. Influence of one object and its legitimacy can and is influential on other factors (e.g. legal, economic, social and cultural). It is also important to highlight that these objects tend to exhibit independence in their functions initially and in short periods. Hence, the legitimacy of Security Council of the UN can be maintained despite the fact that crimes against humanity and human rights in Syria have not been adequately addressed. Mechanisms of legitimating also varies from object to object and the context and situation of that object defines the mechanism to be applied and used regarding the object . 


\section{B. Subjects}

Legitimacy of an object are under the assumption of moral and legal legitimacy that the subject is to be submitted or supported as a legitimate one. Variations apply to subjects similar to objects. If a specific concept of legitimacy is adopted, the subject can vary in terms of their legitimacy accordingly. States have been the traditional form of subjects in terms of international law. Citizens, people of a territorial state, and adherents of a specific religion can also be considered as subjects. In a more recent academic work it was noted that the actual subjects of international law are all the people as individuals in the world. This is a perspective of morality on a higher extent compared to formality . On a similar notion, these concepts from subjects and objects of legitimacy are complex by their nature. Additionally, a state has been suggested to be not a mere subject of international law context but to be a source as wel as an official46. The community, from which the legitimacy of social aspect rises is to be distinguished from subjects that are considered legal or moral forms of legitimacy, as social construct of legitimacy is shaped from both legal and moral. The concept of social legitimacy can attain meaningfulness when it is addressed towards an audience. Its projection must be initiated by an individual or a group to determine legitimacy of an actor. This judgement is based on their norms and standards. The same common standards are to be applied for the concept of legitimating a subject regarding an object, when a judgment is to be held upon. The number of legitimating communities regarding a specific object is not limited and can be overlapped or varying. This is while some communities may hold a higher extent of power compared to others. The vote of public then regarding legitimating can be issued from supreme national court as a representative of community.

\section{Bases (Procedure, Substance and Outcome)}

The final element regarding legitimacy is the base or bedrock of an object that is to be addressed on its legitimacy. Procedures, substances and outcomes are forms of legitimacy in terms of basis. Procedure of legitimacy is referred to a set of framework regarding power and its exercise. These procedures focus on the validity of power as well as changes, or issuance of laws alongside officials or authorities that are to be appointed. Settings, from which laws are made or public participation processes are addressed within such procedures . Aforementioned notion of social legitimacy has been shaped from this aspect of procedure-base legitimacy. Substance of a source as a references is emphasized, compared to actions generated by that specific source.

\section{Court of Justice}

The court of justice is to be guarantee that treaties are interpreted and applied based on the law. This is derived from Article 19 TEU. However, this notion and function of the court has also faced challenges in terms of criticism . Usurpation of power may occur due to the root of judicial inapplicability in terms of politics and guidelines of the court. Hence, the court and its legitimacy has been facing criticism. The concern is not addressed towards all aspects of judicial activities. However, the concern arises when the legitimacy of the court is jeopardized. Therefore, it can be seen that if a notion is not solidly derived from law, it may be the subject of criticism. Legislations, and provision of law regarding treaties is a major requirement in terms of explicit judgements of the court and its subsequent function. The aforementioned statement can lead to a degree of tension between normative and descriptive legitimacy as the court has been given legitimacy in both aspects to regard and address treaties. This further expands to decision making processes of treaties and their interpretation. Constitutional or interpretations of the court as its functions can be examined and evaluated and are subjects to scrutiny. It is also to be noted that the function of court regarding interpretation does not lack legitimacy as it consists of vital elements such as transparency, predictability, and equity. This further aids the path towards retaining both legitimacy aspects of normative and descriptive for the court.

\section{Conclusion}

The main aim of this paper was to provide a better understanding of the topic of legitimacy in the scope of international law through provision of most recent and relevant data surrounding the subject. Legal orders can be under the question in terms of legitimacy as a concept, which can further extend to settings such as, formation, transformation, maintenance, and expansion. As it was noted in this paper, the usage of the word legitimacy has been abused based on the context or the party using its potential as a tool. Stability and degree of efficiency of a state and its governing body is in relation with self-interests, habit and coercion, which can trigger actions or initiatives from an international actor. Furthermore, this can lead to more substantial questions regarding whether or not a specific regime is to be supported or not. Debates surrounding legitimacy can have a significant impact from international lawyers, who can provide an adequate and sufficient comprehension over the law and the values regarding such matters. As it was highlighted in this paper, the subject at hand complex by nature and thus, it requires extensive reviews over the literature as well as analyzing underlying effects and possible future changes. Moral legitimacy in particular, is an aspect that can ignite debates due to the extent that it is implied. The role of courts cannot be neglected as they provide a foundation for international law that is not merely beneficial for the scope of international law but can be beneficial regarding the understanding of procedures. Moreover, compliance and following obligations with an intended degree of commitment is another requirement for advancements of legitimacy both as concept and as usage. For the case of EU and WTO, the notion of legitimacy and its comprehension, articulations over sociological forms of legitimacy can be of aid (normative and descriptive). The signatory parties and rules assigned have received legitimacy from both aspects within EU and WTO. This concern is more vivid, when trade and liberalization of trade is the matter at hand. Moreover, the EU holds legitimacy regarding other issues such as environmental concerns. Hence, fragility, legitimacy, and rights regarding rules and/or exercise of power require a thorough understanding if they are to be adequately implied or dealt with. Acceptance of a legitimacy (descriptive or social) against the right to rule (normative) is a 
key element in terms of actions to be undertaken by the authorities and parties involved. On an international scale, the actors are to come upon a consensus regarding international players and their legitimacy. As previously mentioned, assessments and evaluations are to be made through a clear and justified manner. When necessary requirements of legitimacy have been met on a satisfactory and unambiguous manner, the extent of acceptance is relatively deemed easier. Administrative processes and objective factors can have a significant impact on the outcomes of legitimacy. 